\title{
Influence of Electrostatic Interactions on Behavior of Mixed Rice Glutelin and Alginate Systems: pH and Ionic Strength Effects
}

\author{
Xingfeng $\mathrm{Xu}^{\mathrm{a}, \mathrm{b}}$, Liping Luo ${ }^{\mathrm{a}}$, Chengmei Liu ${ }^{\mathrm{a}, 1^{*}}$, Zipei Zhang ${ }^{\mathrm{b}}$, \\ David Julian McClements ${ }^{\text {b,c, }}$ (** $^{\text {Mem }}$
}

${ }^{a}$ State Key Laboratory of Food Science and Technology, Nanchang University, Nanchang, No. 235 Nanjing East Road, Nanchang 330047, Jiangxi, China.

${ }^{b}$ Department of Food Science, University of Massachusetts, Amherst, MA 01003, USA.

${ }^{c}$ Department of Biochemistry, Faculty of Science, King Abdulaziz University, P. O. Box 80203, Jeddah, 21589, Saudi Arabia

* Corresponding author. State Key Laboratory of Food Science and Technology, Nanchang University, Nanchang, Jiangxi 330047, China. Tel: +86 791 88305872(8106); Fax: +8679188334509

E-mail address: liuchengmei@aliyun.com (C. Liu).

** Corresponding author. Department of Food Science, University of Massachusetts, Amherst, MA 01003, USA. Tel.: +1 (413) 545 1019; fax: +1 (413) 545 1262.

E-mail address: mcclements@foodsci.umass.edu (D.J. McClements).

${ }^{1}$ These authors contributed equally to this manuscript 


\begin{abstract}
The influence of $\mathrm{pH}(2-7)$ and ionic strength (0 to $200 \mathrm{mM} \mathrm{NaCl})$ on the properties of hydrolyzed rice glutelin (HRG), alginate, and their mixtures in aqueous solutions was investigated using turbidity, $\zeta$-potential, and microscopy measurements. Soluble or insoluble complexes could be formed between HRG and alginate by manipulating solution conditions such as $\mathrm{HRG}$ :alginate ratio, $\mathrm{pH}$, and ionic strength. Relatively small complexes that were relatively stable to aggregation and sedimentation over a wide range of $\mathrm{pH}$ conditions could be formed using a 3:1 HRG to alginate mass ratio. The addition of salt $(\mathrm{NaCl})$ to solutions containing HRG-alginate complexes weakened the electrostatic attraction between them, which led to release of the protein. As a result, the protein molecules tended to interact with other protein molecules (rather than polysaccharide molecules) leading to the formation of precipitates and sediments. The electrostatic complexes formed in this study may be a useful means of extending the utilization of rice proteins as functional ingredients in food and beverage products.
\end{abstract}

Keywords: rice glutelin; alginate; electrostatic complex; turbidity; ionic strength 


\section{Introduction}

Knowledge of the interactions between proteins and polysaccharides is of great interest in the food, agricultural, and personal care industries because of their ability to generate specific functional attributes in materials, such as texturization, stabilization, and encapsulation (Fioramonti, Perez, Aríngoli, Rubiolo, \& Santiago, 2014; Li, Liu, et al., 2016; Razzak, Kim, \& Chung, 2016). In aqueous solutions, proteins and polysaccharides may interact with each other through various types of attractive or repulsive forces, van der Waals, electrostatic, steric, hydrogen bonding, or hydrophobic. Depending on the nature of the interactions involved, the mixed system may exist as a miscible molecular solution, a colloidal dispersion of protein-polysaccharide complexes, or segregated phases (Bokkhim, Bansal, Grondahl, $\&$ Bhandari, 2015). The nature of any colloidal dispersion formed depends on the molecular characteristics of the biopolymers involved (charge density, molar mass, conformation, flexibility, and concentration), environmental conditions ( $\mathrm{pH}$ and ionic strength), and the biopolymer mixing ratio (Souza \& Garcia-Rojas, 2015; Stone \& Nickerson, 2012; Stone, Teymurova, Chang, Cheung, \& Nickerson, 2015; Yuan, Wan, Yang, \& Yin, 2014). For electrically charged polysaccharides, electrostatic interactions play a particularly important role in the formation of protein-polysaccharide complexes. At $\mathrm{pH}$ values around and below its isoelectric point (pI), a protein carries positively charges groups that can interact with anionic polysaccharides by electrostatic attraction (Khalesi, Emadzadeh, Kadkhodaee, \& Fang, 2015). The resulting electrostatic complexes formed can be used to create desirable functional attributes within food and beverage products. In this study, we examined the possibility of improving the solubility characteristics of a hydrolyzed rice protein by forming electrostatic complexes between it and an anionic polysaccharide.

Rice glutelin is the major storage protein in rice, and has been reported to have a high nutritive value, to lower cholesterol levels, and to be hypoallergenic (Du, et al., 2013). For this reason, there is considerable interest in using rice glutelin as a functional ingredient in the food industry. Nevertheless, its utilization in many food 
and beverage products is currently limited due to the low water-solubility of the native protein. In a previous study, we used trypsin treatment to fabricate a partially hydrolyzed rice glutelin (HRG) ingredient that had a relatively high water-solubility under neutral $\mathrm{pH}$ conditions (Xu, et al., 2016). However, this HRG was still water-insoluble at $\mathrm{pH}$ values near its isoelectric point, which may restrict its application in many food and beverage products. We therefore examined the possibility of extending the range of $\mathrm{pH}$ conditions where HRG could be used by forming electrostatic complexes with polysaccharides. A previous study reported that the physical and oxidative stability of rice protein emulsions was improved by addition of xanthan gum, which was attributed to an increase in aqueous phase viscosity, as well as to an increase in the electrosteric repulsion between the droplets (Chen, et al., 2016). Another study reported that mixtures of deamidated rice protein and dextran underwent segregative phase separation through a thermodynamic incompatibility mechanism ( $\mathrm{Li}$, et al., 2010). More recently, the phase behavior of deamidated rice protein and $\kappa$-carrageenan/ dextran mixtures has been studied (Li, Liu, et al., 2016). These researchers suggested that the main driving forces for the observed phase separation in this system were depletion and electrostatic interactions. However, improving the physical stability of rice glutelin in aqueous solutions by addition of polysaccharides has rarely been reported.

Alginate $(\mathrm{AL})$ is an anionic linear polysaccharide that is composed of $(1,4)-\beta-D-m a n n u r o n i c ~ a c i d ~ a n d ~(1,4)-\alpha-L$-guluronic acid units, which occurs naturally in brown marine algae (Razzak, et al., 2016). It is widely used in the food industry as a natural stabilizer, thickener, and gelling agent (Harnsilawat, Pongsawatmanit, \& McClements, 2006; Razzak, et al., 2016). Alginate has been reported to form either soluble or insoluble complexes with various proteins in aqueous solutions, including pea protein (Klemmer, Waldner, Stone, Low, \& Nickerson, 2012), $\beta$-lactoglobulin (Harnsilawat, et al., 2006), lactoferrin (Bokkhim, et al., 2015), whey protein (Fioramonti, et al., 2014) and fish gelatin (Razzak, et al., 2016). These studies reported that the formation of soluble or insoluble complexes between alginate and proteins was highly dependent on $\mathrm{pH}$ (Harnsilawat, et al., 2006), biopolymer ratio 
(Klemmer, et al., 2012), and ionic strength (Razzak, et al., 2016). However, the behavior of HRG and alginate mixtures has not previously been reported.

In this study, we characterized the major factors affecting the interactions between HRG and alginate in aqueous solutions using turbidity, $\zeta$-potential, and optical microscopy measurements. The formation of electrostatic complexes under different $\mathrm{pH}$, ionic strength, and mass ratio conditions were studied. This study could be used to facilitate the design of rice protein-based food ingredients with more desirable functional properties.

\section{Materials and Methods}

\subsection{Materials}

Rice glutelin (93.42 wt\%, dry basis) was provided by Golden Agriculture Biotech Company Limited (Jiangxi, China). Sodium chloride, alginate, sodium azide, trypsin and other chemicals were of analytical grade and were purchased from Sigma-Aldrich (Sigma Chemical Co., St. Louis, MO). Corn oil was obtained from a commercial food supplier (Mazola, ACH Food Companies, Memphis, TN). Double-distilled water was used to prepare all solutions.

\subsection{Preparation of hydrolyzed rice glutelin (HRG)}

Hydrolyzed protein was prepared using trypsin according to a method described previously (Xu, et al., 2016). $2 \mathrm{~g}$ of rice glutelin was added to double-distilled water (30 $\mathrm{mL})$ with constant stirring for $1 \mathrm{~h}$. Trypsin was then added after the $\mathrm{pH}$ and temperature had been adjusted to the required values $\left(\mathrm{pH}=8,50^{\circ} \mathrm{C}\right)$. After $4.2 \mathrm{~min}$ of hydrolysis, the dispersion was heated to $95{ }^{\circ} \mathrm{C}$ for $10 \mathrm{~min}$ to inactivate the trypsin, adjusted to $\mathrm{pH} 7.0$ using $\mathrm{HCl}$ or $\mathrm{NaOH}$, and then immediately cooled to room temperature by placing the test tube in water. The $\mathrm{pH}$ of the suspension was kept constant by addition of $2.5 \mathrm{M} \mathrm{NaOH}$ during the entire period of hydrolysis. The mixture was centrifuged (TGL-20B, Anting Scientific Instrument Factory, Shanghai, China) at $4800 \mathrm{~g}$ for $10 \mathrm{~min}$ and the supernatant was freeze-dried. The degree of hydrolysis (DH) 
was analyzed using a pH-stat method described previously (Adler-Nissen, 1986). Finally, HRG with $2 \%$ degree of hydrolysis was obtained.

\subsection{Preparation of biopolymer mixtures}

Aqueous solutions of HRG (3 wt $\%)$ and alginate (2 wt $\%)$ were separately prepared by dispersing weighed amonts of the powdered ingredients in double-distilled water (containing $0.02 \mathrm{wt} \%$ sodium azide as an antimicrobial). Each solution was then adjusted $\mathrm{pH}$ to 7.00 using $\mathrm{HCl}$ or $\mathrm{NaOH}$, and then stirred for at least $5 \mathrm{~h}$ at room temperature to ensure full dissolution. Mixed solutions containing HRG $(0.3 \mathrm{wt} \%)$ and alginate $(0-0.3 \mathrm{wt} \%)$ were prepared by mixing biopolymer and buffer solutions together at different volume ratios to obtain the required final concentrations. The resulting solutions were then stirred for at least $30 \mathrm{~min}$ to ensure complete dispersion and readjusted to $\mathrm{pH} 7.00$ using $0.1 \mathrm{M} \mathrm{NaOH}$ prior.

\subsection{Turbidity measurements}

The turbidity of dispersions containing HRG and alginate were measured with a UV-visible spectrophotometer at $600 \mathrm{~nm}$ (Ultrospec 3000 pro, Biochrom Ltd., Cambridge, UK) using plastic cuvettes ( $1 \mathrm{~cm}$ path length). Solution $\mathrm{pH}$ was changed by dropwise addition of $\mathrm{HCl}$ from 7.0 to 2.0. Dilution effects were minimized by using a gradient of $\mathrm{HCl}$ concentrations based on $\mathrm{pH}(0.05 \mathrm{M}>\mathrm{pH} 3.6,0.5 \mathrm{M}>\mathrm{pH} 2.8,1.0 \mathrm{M}>$ pH 2.0) (J. Liu, Shim, Wang, \& Reaney, 2015). The effect of ionic strength on HRG-alginate interactions was also measured by adding $\mathrm{NaCl}$ at a concentration of 0-200 $\mathrm{mM}$ while keeping the ratio of $\mathrm{HRG}$ to alginate constant at $3: 1(\mathrm{w} / \mathrm{w})$. Homogenous HRG and alginate solutions with corresponding concentrations were used as controls.

\section{5 ל-potential measurement}

The $\zeta$-potential of solutions at different $\mathrm{pH}$ (2-7) was measured using particle microelectrophoresis (Zetasizer Nano ZS series, Malvern Instruments, Worcestershire, UK). The solutions were measured without dilution. Duplicate measurements were performed at $25^{\circ} \mathrm{C}$ on each sample. 


\subsection{Microscopy}

Microscopic images of samples were measured using a light microscope (C1 80i Digital Eclipse, Nikon, Tokyo, Japan/Meliville, NY, USA) with a $60 \times$ objective lens. Aliquots $(10 \mu \mathrm{L})$ of sample were placed onto microscope slides and then carefully covered with a coverslip. The images were captured from at least four similar images.

\subsection{Statistical analyses}

Statistical analysis was carried out using an one-way ANOVA test using SPASS 19.0 (SPSS Inc., Chicago, IL). Significant differences among samples were taken as $p$ $<0.05$. Each experiment was performed in triplicate and the results are reported as means values \pm standard deviation $(\mathrm{SD})$.

\section{Results and discussion}

Electrostatic interactions between proteins and polysaccharides are related to the charge characteristics of each biopolymer, the biopolymer ratio, $\mathrm{pH}$, and ionic strength (Fioramonti, et al., 2014; Rodríguez Patino \& Pilosof, 2011). Consequently, we focused on the impact of these parameters on the formation of HRG-alginate complexes in the current study. Our main aim was to find system conditions where clear solutions or stable colloidal dispersions could be formed using the hydrolyzed rice protein, since these systems may be suitable for application in food and beverage products.

\subsection{Effects of polysaccharide concentration on complex formation}

Initially, the impact of polysaccharide-to-protein ratio on complex formation was examined by keeping the HRG level constant $(0.3 \mathrm{wt} \%)$ and increasing the alginate level ( 0 to $0.25 \%)$. The $\mathrm{pH}$ dependence of the turbidity of the various biopolymer solutions was measured (Fig. 1a). The pure alginate solution remained transparent over the whole $\mathrm{pH}$ range studied (data not shown), indicating that the alginate molecules did not form complexes large enough to scatter light. This was presumably because of the strong electrostatic repulsion between the negatively charged alginate molecules 
(Fig. 2). The turbidity of the pure HRG solution remained relatively low when the $\mathrm{pH}$ was reduced from 7 to 6 , then it increased from $\mathrm{pH} 6$ to 4 , but then it decreased from $\mathrm{pH}$ 4 to 2 (Fig. 1a). In addition, digital photographs of the samples showed that they were transparent at pH 6 and 7, but contained white sediment at the bottom of the test tubes at pH 5 to 2 (Fig. 1b). These results confirm that the water-solubility of the hydrolyzed rice protein was relatively good around neutral $\mathrm{pH}$, but poor at more acidic $\mathrm{pH}$ values.

For this reason, the impact of different levels of alginate on the solubility characteristics of the HRG was examined. The $\mathrm{pH}$ dependence of the turbidity and appearance of the mixed systems depended on alginate concentration (Fig. 1). It should be noted that the photographs of the samples show their overall appearance after settling, whereas the turbidity measurements were carried out after the samples were made homogeneous by inverting the test tubes. In general, as the $\mathrm{pH}$ was decreased from $\mathrm{pH} 7$ to 2 , the turbidity of the HRG-alginate solutions initially increased, then reached a maximum value, and then either decreased or remained fairly constant depending on alginate concentration. At $\mathrm{pH} 6$ and 7, increasing the amount of alginate in the solutions caused a slight dose-dependent increase in turbidity, which may have been due to the slight turbidity of the alginate solutions or due to the formation of soluble complexes (Fig. 2). Soluble electrostatic complexes may form under conditions where both the protein and polysaccharide have negative charges due to the binding of anionic groups on the alginate molecules to cationic patches on the HRG surfaces (Razzak, et al., 2016). At most pH values, the addition of alginate suppressed the formation of white sediment at the bottom of the test tubes that was observed in the systems containing pure HRG (Fig. 1b). Instead, either a clear solution or a relatively stable cloudy colloidal dispersion was formed. These results suggest that it may be possible to incorporate hydrolyzed rice protein into aqueous-based products over a broad range of $\mathrm{pH}$ values when it is used in combination with an anionic polysaccharide. This result is in agreement with previous studies that have shown that the water-dispersibility of other types of proteins can be improved by forming electrostatic complexes with alginate (Zhang, Zhang, Decker, \& McClements, 2015). 
The turbidity measurements and visual observations suggest that mixed systems containing different types of complexes could be formed depending on biopolymer ratio and $\mathrm{pH}$. Soluble complexes tended to be formed at $\mathrm{pH}$ values well above the isoelectric point of the hydrolyzed rice protein leading to fairly clear solutions or only slightly turbid colloidal dispersions. Coacervate particles appeared to be formed at $\mathrm{pH}$ values around and slightly below the isoelectric point of the protein, leading to the generation of cloudy colloidal dispersions. Relatively large insoluble complexes (precipitates) were formed at $\mathrm{pH}$ values well below the isoelectric point leading to the formation of a sediment. Previous studies suggest that the formation of protein-polysaccharide complexes follows a number of sequential steps when the $\mathrm{pH}$ is reduced from well above to well below the protein's isoelectric point: (i) an intimate mixture of non-complexed protein and polysaccharide molecules is formed due to strong electrostatic repulsion; (ii) soluble complexes containing only a few biopolymer molecules are formed due to electrostatic attraction between positive patches on the protein molecules and negative groups on the polysaccharide molecules; (iii) coacervates are formed consisting of numerous protein and polysaccharide molecules loosely packed into relatively small colloidal particles; and, (iv) precipitates are formed consisting of many protein and polysaccharide molecules tightly packed into a separate phase leading to sedimentation; (v) an intimate mixture is again formed when the polysaccharide loses its negative charge well below the $\mathrm{pK}_{\mathrm{a}}$ value of its charged groups (Li, et al., 2012; Weinbreck, De Vries, Schrooyen, \& De Kruif, 2003). In our study, $0.3 \%$ HRG solutions containing 0.05 to $0.25 \mathrm{wt} \%$ alginate formed relatively stable colloidal suspensions from $\mathrm{pH} 3$ to 7 , but sediments were observed in many of the samples at $\mathrm{pH} 2$ (Fig. 1b). Moreover, the 0.3\% HRG solutions containing $0.1 \mathrm{wt} \%$ alginate remained relatively transparent or only slightly turbid across the entire $\mathrm{pH}$ range studied, indicating that they probably contained soluble complexes or small coacervate particles.

The $\mathrm{pH}$ dependence of the $\zeta$-potential of HRG solutions containing different alginate concentrations was also determined (Fig. 2). The $\zeta$-potential of pure HRG solutions (no alginate) changed from highly negative $(-39.3 \mathrm{mV}$ ) at $\mathrm{pH} 7$ to 
moderately positive $(+14.6 \mathrm{mV})$ at $\mathrm{pH} 2$, with a point of zero charge around $\mathrm{pH} 4$, which corresponds to the isoelectric point of this protein. The $\zeta$-potential of pure alginate solutions went from strongly negative $(-63.6 \mathrm{mV})$ at $\mathrm{pH} 7$ to slightly negative $(-5.54 \mathrm{mV})$ at $\mathrm{pH}$ 2. The lower magnitude of the negative charge on the alginate molecules at highly acidic conditions can be attributed to the fact that the carboxyl groups $\left(\mathrm{pK}_{\mathrm{a}} \approx 1.88\right)$ along the alginate backbone became partially protonated at this $\mathrm{pH}$ (Klemmer, et al., 2012). All the HRG-alginate mixtures exhibited fairly similar trends in the $\zeta$-potential versus $\mathrm{pH}$ profiles. The $\zeta$-potential of the mixed systems was appreciably more negative than the pure HRG solutions, which suggested that electrostatic complexes were formed by the protein and polysaccharide molecules. The origin of this effect is electrostatic attraction between the carboxyl groups on the alginate and cationic groups on the protein surfaces, even at $\mathrm{pH}$ values above the isoelectric point where both the protein and polysaccharide have a net negative charge. A similar result has been reported for other combinations of globular proteins and anionic polysaccharides, such as wheat protein and pectin (Qiu, Zhao, \& McClements, 2015) and pea protein and gum arabic (S. Liu, Low, \& Nickerson, 2009). Interestingly, as the alginate concentration was increased, the $\zeta$-potential of the mixed system approached the value of the pure alginate solution. This suggests that the protein molecules made little contribution to the overall $\zeta$-potential signal of the mixed system, presumably because the high number of negative charges on the polysaccharide molecules dominated the positive charges on the surfaces of the protein molecules. A similar result has been reported for WPI-xanthan gum systems (Benichou, Aserin, Lutz, \& Garti, 2007).

\subsection{Aggregation characteristics of mixed biopolymer systems}

In this section, the formation of protein-polysaccharide complexes was characterized in more detail for HRG $(0.3 \%)$ in the absence or presence of the optimum amount of alginate $(0.1 \%)$ established in the previous section. Again, complex formation was monitored by measuring changes in turbidity versus $\mathrm{pH}$ using an acid titration (Fig. 3). 
In the absence of alginate, the pure HRG solution remained relatively transparent from $\mathrm{pH} 7$ to 6 , exhibited a steep increase in turbidity from $\mathrm{pH} 5.8$ to 3.9, and then exhibited a decrease in turbidity from $\mathrm{pH} 3.8$ to 2 . The turbidity peak observed around $\mathrm{pH} 3.9$ corresponded to the point of zero charge observed in the $\zeta$-potential measurements (Fig. 2). This suggests that the maximum amount of protein aggregation occurred when the protein had the lowest net charge, which can be attributed to the reduction in electrostatic repulsion between the protein molecules. The turbidity decreased as the $\mathrm{pH}$ was raised above or lowered below this value because the increase in electrostatic repulsion between the protein molecules partially inhibited their aggregation. The optical microscopy images clearly showed that there were large aggregates within the protein solutions around the isoelectric point of the protein (Fig. 3, inset).

The presence of alginate $(0.1 \%)$ in the HRG solution repressed the large increase in turbidity normally observed around the protein's isoelectric point, and there was no evidence of large aggregates in the microscopy images (Fig. 3). The turbidity of the mixed protein-polysaccharide solution was relatively low at $\mathrm{pH} 7.0$ due to the relatively strong electrostatic repulsion between the anionic alginate and HRG molecules. In this case, the two biopolymers probably formed a mixture of intermingled molecules or small soluble complexes. As the $\mathrm{pH}$ was decreased, the turbidity began to increase slightly around $\mathrm{pH} 5.8$ suggesting the formation of soluble protein-polysaccharide complexes. When the $\mathrm{pH}$ was reduced further, there was a steeper increase in turbidity near $\mathrm{pH} 3.6$, which is probably due to association of the soluble complexes leading to the formation of coacervates. These coacervates remained dispersed in the aqueous phase as a colloidal suspension that visibly appeared turbid. The stability of the coacervate suspension to coalescence can be attributed to the relatively strong electrostatic repulsion between the coacervate particles due to their relatively high negative charge (Fig. 2). Similar results have been reported in other studies of electrostatic complexation between proteins and anionic polysaccharides, such as casein and alginate (Zhang, et al., 2015), pea protein and alginate (Klemmer, et al., 2012), and napin protein and carboxylated alginate (Stone, et al., 2014). 
Complexation of HRG and alginate is mainly driven by electrostatic interactions. Consequently, the addition of salts to the solutions would be expected to alter the nature of the complexes formed by screening any attractive or repulsive electrostatic interactions in the system. For this reason, the impact of $\mathrm{NaCl}$ addition on the properties of HRG solutions $(0.3 \%)$ in the absence and presence of alginate $(0.1 \%)$ was investigated.

\subsection{Effect of $\mathrm{NaCl}$ on the properties of HRG solutions}

The effect of ionic strength on the turbidity-pH profiles of pure HRG solutions was measured (Fig. 4a). All the samples exhibited the same general trend as the $\mathrm{pH}$ was decreased from 7 to 2: first the turbidity increased and then decreased. Nevertheless, there were some noticeable differences between the turbidity-pH profiles depending on salt level. The turbidity of the HRG solutions increased in the presence of $\mathrm{NaCl}$ at $\mathrm{pH}$ values somewhat above ( $\mathrm{pH} 6.2$ to 5.2) and somewhat below ( $\mathrm{pH} 3.4$ to 2.0) the protein's isoelectric point. This suggested, that the addition of salt may have screened the electrostatic repulsion between the protein molecules, thereby widening the range of $\mathrm{pH}$ values where isoelectric precipitation occurred. Indeed, protein precipitation and sedimentation was observed at a higher $\mathrm{pH}$ value $(\mathrm{pH} 5.5)$ in the presence of $\mathrm{NaCl}$ than in its absence (Fig. 4b). Conversely, there was a pronounced decrease in turbidity around the isoelectric point of the protein, i.e., from pH 5.2 to 3.4 (Fig. 4a). This effect may have been due to a weakening of the electrostatic attraction between positive and negative patches on neighboring protein surfaces leading to smaller insoluble protein particles (Stone, et al., 2012).

The effect of ionic strength on the $\zeta$-potential-pH profile of HRG solutions was also measured (Fig. 5). All the samples exhibited fairly similar general trends in the $\mathrm{pH}$ dependence of the $\zeta$-potential, going from negative at high $\mathrm{pH}$ to positive at low pH. Nevertheless, there were appreciable differences in the magnitudes of the $\zeta$-potential depending on salt level. In the absence of $\mathrm{NaCl}$, the $\zeta$-potential of $\mathrm{HRG}$ changed from negative $(-39.3 \mathrm{mV})$ to positive $(+14.6 \mathrm{mV})$ when $\mathrm{pH}$ was adjusted from 7 to 2, with a point of zero charge near $\mathrm{pH}$ 3.8. As the salt concentration was 
increased, the magnitude of the $\zeta$-potential at both low and high $\mathrm{pH}$ values decreased, which can be attributed to electrostatic screening effects. On the other hand, the point of zero charge was not strongly affected by the $\mathrm{NaCl}$ concentration, which suggests that specific salt ions $\left(\mathrm{Na}^{+}\right.$or $\left.\mathrm{Cl}^{-}\right)$did not preferentially bind to the surfaces of the protein molecules.

\subsection{Effect of $\mathrm{NaCl}$ on the properties of $\mathrm{HRG}$-alginate solutions}

The effect of ionic strength on the turbidity and appearance of HRG-alginate solutions was also determined as a function of $\mathrm{pH}$ (Fig. 6), since salt ions would be expected to influence the attractive and repulsive electrostatic interactions between the two types of biopolymer (Hadian, et al., 2016; Schmitt, Aberkane, Sanchez, Phillips, \& Williams, 2009). Interestingly, salt addition had a much larger impact on the $\mathrm{pH}$ dependence of the turbidity and appearance of the mixed systems than for the pure HRG systems. In a broad $\mathrm{pH}$ range around the isoelectric point of the protein ( $\mathrm{pH} 3.5$ to 6.5), increasing the $\mathrm{NaCl}$ level in the mixed systems caused an appreciable increase in turbidity (Fig. 6a) and led to the formation of visible sediments in many systems (Fig. 6b). In addition, the $\mathrm{pH}$ dependence of the turbidity and appearance of the mixed systems became more similar to those of the pure protein systems in the presence of salt. These results suggest that the addition of even low levels of salt (50 $\mathrm{mM} \mathrm{NaCl}$ ) weakened the electrostatic attraction between the protein and polysaccharide molecules, thereby allowing the protein molecules to interact with each other rather than with the anionic polysaccharide molecules. Similar effects have been reported for other protein-anionic polysaccharide combinations, such as gelatin-alginate (Razzak, et al., 2016) and whey protein-carrageenan (Weinbreck, Nieuwenhuijse, Robijn, \& de Kruif, 2004). As mentioned earlier, the pH range where visible precipitation and sedimentation occurred in the mixed systems increased in the presence of salt (Fig. 6b), which suggests that the electrostatic complexes would not remain intact in foods that had relatively high salt contents.

The effect of $\mathrm{NaCl}$ concentration on the $\zeta$-potential-pH profile of the HRG-alginate mixed was also measured (Fig. 7). All the mixed systems had a net 
negative charge at all $\mathrm{pH}$ values studied, but the magnitude of the $\zeta$-potential decreased from $\mathrm{pH} 7$ to 2 . The relatively steep decrease in the $\zeta$-potential from $\mathrm{pH} 4$ to 2 observed in all systems can be attributed to protonation of the carboxyl groups on the HRG and alginate molecules around their $\mathrm{pK}_{\mathrm{a}}$ values. The magnitude of the $\zeta$-potential in the mixed systems decreased over the entire $\mathrm{pH}$ range as the $\mathrm{NaCl}$ concentration was increased, which can be partly attributed to electrostatic screening effects (Guzey \& McClements, 2006; Li, Li, Shen, Niu, \& Fu, 2016). In addition, it is likely that the electrostatic attraction between the protein and polysaccharide molecules was weakened at higher salt levels, which promoted the release of some of the protein molecules from the complexes thereby altering the electrical properties of the system.

\section{Conclusions}

The present study demonstrated that the range of $\mathrm{pH}$ values where hydrolyzed rice protein could be successfully incorporated into aqueous solutions could be extended by addition of alginate. This effect was attributed to the formation of an electrostatic HRG-alginate complex, which inhibited isoelectric precipitation of the protein. A protein-to-polysaccharide mass ratio of 3:1 was found to produce either clear solutions, stable turbid colloidal suspensions, or unstable precipitates depending on solution $\mathrm{pH}$. The addition of $\mathrm{NaCl}$ to these systems weakened the electrostatic interactions in the system, which released some of the protein from the complexes and led to sedimentation. The native rice glutelin would not have same phenomenon because it has low solubility even under neutral conditions and limited protein molecules could interact with alginate when $\mathrm{pH}$ changed from 7 to lower. These results may be useful for the design and formulation of food or beverage products fortified with rice proteins.

\section{Acknowledgements}

This study was supported by the Freedom Explore Program of State Key Laboratory 
of Food Science and Technology of Nanchang University (No. SKLF-ZZB-201512).

This material was also partly based upon work supported by the Cooperative State Research, Extension, Education Service, USDA, Massachusetts Agricultural Experiment Station (MAS00491) and a USDA, NRI Grant (2013-03795).

\section{References}

Adler-Nissen, J. (1986). Enzymic hydrolysis of food proteins: Elsevier Applied Science Publishers.

Benichou, A., Aserin, A., Lutz, R., \& Garti, N. (2007). Formation and characterization of amphiphilic conjugates of whey protein isolate (WPI)/xanthan to improve surface activity. Food Hydrocolloids, 21(3), 379-391.

Bokkhim, H., Bansal, N., Grondahl, L., \& Bhandari, B. (2015). Interactions between different forms of bovine lactoferrin and sodium alginate affect the properties of their mixtures. Food Hydrocolloids, 48, 38-46.

Chen, X., Li, W., Zhao, Q., Selomulya, C., Zhu, X., \& Xiong, H. (2016). Physical and Oxidative Stabilities of O/W Emulsions Formed with Rice Dreg Protein Hydrolysate: Effect of Xanthan Gum Rheology. Food and Bioprocess Technology, 1-11.

Du, Y., Shi, S., Jiang, Y., Xiong, H., Woo, M. W., Zhao, Q., Bai, C., Zhou, Q., \& Sun, W. (2013). Physicochemical properties and emulsion stabilization of rice dreg glutelin conjugated with $\mathrm{K}$-carrageenan through Maillard reaction. Journal of the Science of Food and Agriculture, 93(1), 125-133.

Fioramonti, S. A., Perez, A. A., Aríngoli, E. E., Rubiolo, A. C., \& Santiago, L. G. (2014). Design and characterization of soluble biopolymer complexes produced by electrostatic self-assembly of a whey protein isolate and sodium alginate. Food Hydrocolloids, 35, 129-136.

Guzey, D., \& McClements, D. J. (2006). Formation, stability and properties of multilayer emulsions for application in the food industry. Advances in colloid and interface science, 128, 227-248.

Hadian, M., Hosseini, S. M. H., Farahnaky, A., Mesbahi, G. R., Yousefi, G. H., \& Saboury, A. A. (2016). Isothermal titration calorimetric and spectroscopic studies of $\beta$-lactoglobulin-water-soluble fraction of Persian gum interaction in aqueous solution. Food Hydrocolloids, 55, 108-118.

Harnsilawat, T., Pongsawatmanit, R., \& McClements, D. (2006). Characterization of $\beta$-lactoglobulinsodium alginate interactions in aqueous solutions: a calorimetry, light scattering, electrophoretic mobility and solubility study. Food Hydrocolloids, 20(5), 577-585.

Khalesi, H., Emadzadeh, B., Kadkhodaee, R., \& Fang, Y. (2015). Whey protein isolate-Persian gum interaction at neutral $\mathrm{pH}$. Food Hydrocolloids.

Klemmer, K., Waldner, L., Stone, A., Low, N., \& Nickerson, M. (2012). Complex coacervation of pea protein isolate and alginate polysaccharides. Food Chemistry, 130(3), 710-715.

Li, Fang, Y., Al-Assaf, S., Phillips, G. O., Yao, X., Zhang, Y., Zhao, M., Zhang, K., \& Jiang, F. (2012). Complexation of bovine serum albumin and sugar beet pectin: Structural transitions and phase diagram. Langmuir, 28(27), 10164-10176.

Li, Li, K., Shen, Y., Niu, F., \& Fu, Y. (2016). Influence of pure gum on the physicochemical properties of whey protein isolate stabilized oil-in-water emulsions. Colloids and Surfaces $A$ : 
Physicochemical and Engineering Aspects.

Li, Liu, Y., Li, N., Xie, D., Yu, J., Wang, F., \& Wang, J. (2016). Studies of phase separation in soluble rice protein/different polysaccharides mixed systems. LWT-Food Science and Technology, 65, 676-682.

Li, Liu, Y., Yi, C., Cheng, Y., Zhou, S., \& Hua, Y. (2010). Microstructure and rheological properties of mixtures of acid-deamidated rice protein and dextran. Journal of Cereal Science, 51(1), 7-12.

Liu, J., Shim, Y. Y., Wang, Y., \& Reaney, M. J. (2015). Intermolecular interaction and complex coacervation between bovine serum albumin and gum from whole flaxseed (Linum usitatissimum L.). Food Hydrocolloids, 49, 95-103.

Liu, S., Low, N. H., \& Nickerson, M. T. (2009). Effect of pH, salt, and biopolymer ratio on the formation of pea protein isolate- gum arabic complexes. Journal of agricultural and food chemistry, 57(4), 1521-1526.

Qiu, C., Zhao, M., \& McClements, D. J. (2015). Improving the stability of wheat protein-stabilized emulsions: Effect of pectin and xanthan gum addition. Food Hydrocolloids, 43, 377-387.

Razzak, M. A., Kim, M., \& Chung, D. (2016). Elucidation of aqueous interactions between fish gelatin and sodium alginate. Carbohydrate Polymers.

Rodríguez Patino, J. M., \& Pilosof, A. M. (2011). Protein-polysaccharide interactions at fluid interfaces. Food Hydrocolloids, 25(8), 1925-1937.

Schmitt, C., Aberkane, L., Sanchez, C., Phillips, G., \& Williams, P. (2009). Protein-polysaccharide complexes and coacervates. Handbook of hydrocolloids, 420-476.

Souza, C. J., \& Garcia-Rojas, E. E. (2015). Effects of salt and protein concentrations on the association and dissociation of ovalbumin-pectin complexes. Food Hydrocolloids, 47, 124-129.

Stone, A. K., \& Nickerson, M. T. (2012). Formation and functionality of whey protein isolate-(kappa-, iota-, and lambda-type) carrageenan electrostatic complexes. Food Hydrocolloids, 27(2), 271-277.

Stone, A. K., Teymurova, A., Chang, C., Cheung, L., \& Nickerson, M. T. (2015). Formation and functionality of canola protein isolate with both high-and low-methoxyl pectin under associative conditions. Food Science and Biotechnology, 24(4), 1209-1218.

Stone, A. K., Teymurova, A., Dang, Q., Abeysekara, S., Karalash, A., \& Nickerson, M. T. (2014). Formation and functional attributes of electrostatic complexes involving napin protein isolate and anionic polysaccharides. European Food Research and Technology, 238(5), 773-780.

Weinbreck, De Vries, R., Schrooyen, P., \& De Kruif, C. (2003). Complex coacervation of whey proteins and gum arabic. Biomacromolecules, 4(2), 293-303.

Weinbreck, Nieuwenhuijse, H., Robijn, G. W., \& de Kruif, C. G. (2004). Complexation of whey proteins with carrageenan. Journal of agricultural and food chemistry, 52(11), 3550-3555.

Xu, X., Liu, W., Liu, C., Luo, L., Chen, J., Luo, S., McClements, D. J., \& Wu, L. (2016). Effect of limited enzymatic hydrolysis on structure and emulsifying properties of rice glutelin. Food Hydrocolloids, 61, 251-260.

Yuan, Y., Wan, Z.-L., Yang, X.-Q., \& Yin, S.-W. (2014). Associative interactions between chitosan and soy protein fractions: Effects of $\mathrm{pH}$, mixing ratio, heat treatment and ionic strength. Food Research International, 55, 207-214.

Zhang, Z., Zhang, R., Decker, E. A., \& McClements, D. J. (2015). Development of food-grade filled hydrogels for oral delivery of lipophilic active ingredients: $\mathrm{pH}$-triggered release. Food Hydrocolloids, 44, 345-352. 
Fig.1a

(a)

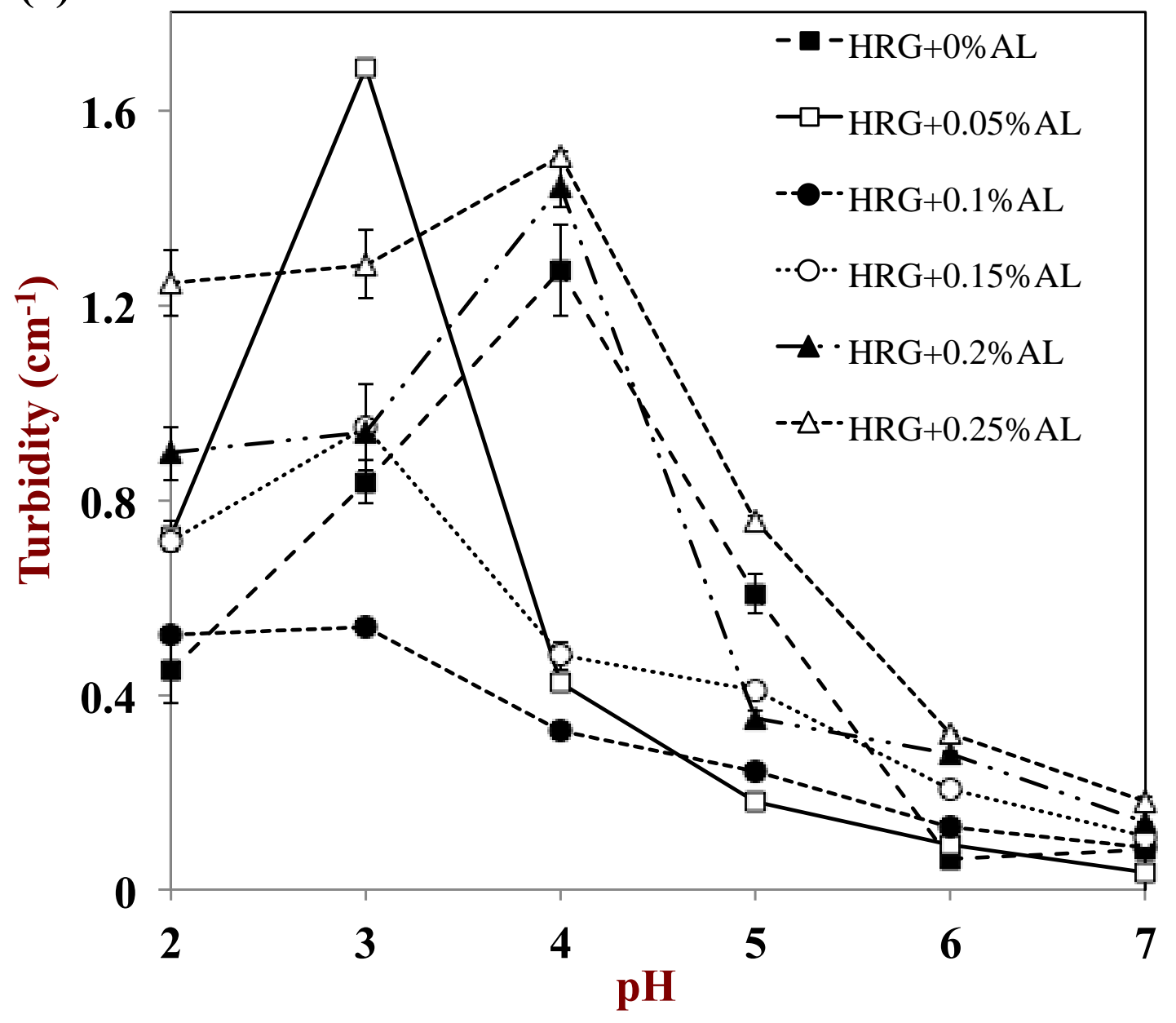


Fig.1b

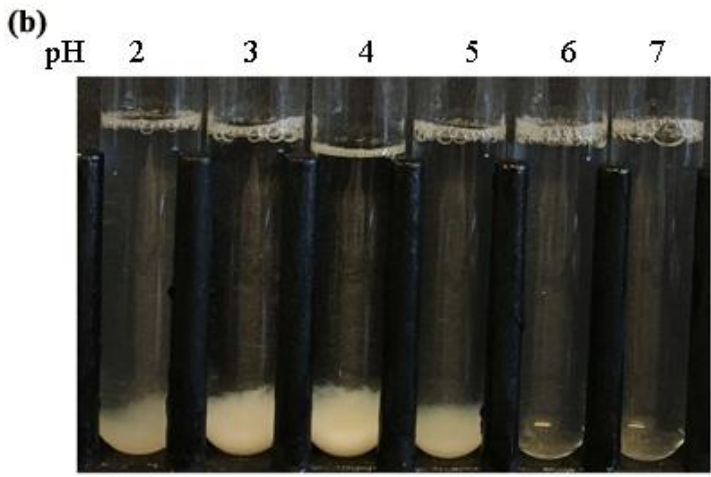

$0.3 \% \mathrm{HRG}$

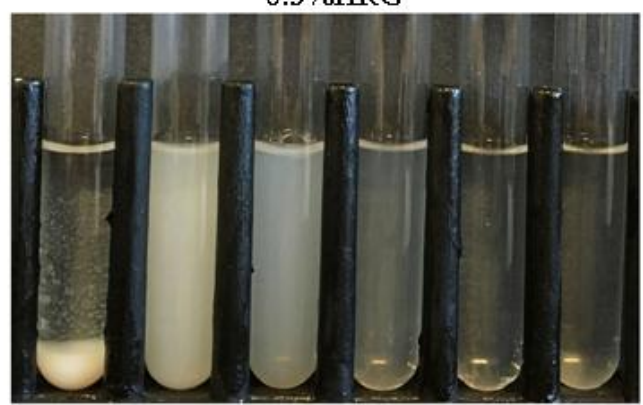

$0.3 \% \mathrm{HRG}+0.05 \%$ Alginate

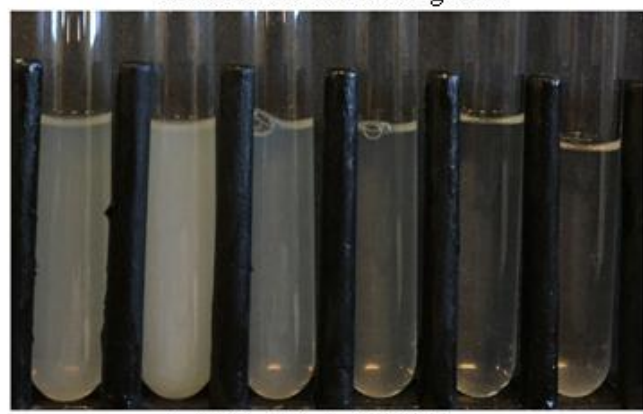

$0.3 \% \mathrm{HRG}+0.1 \%$ Alginate

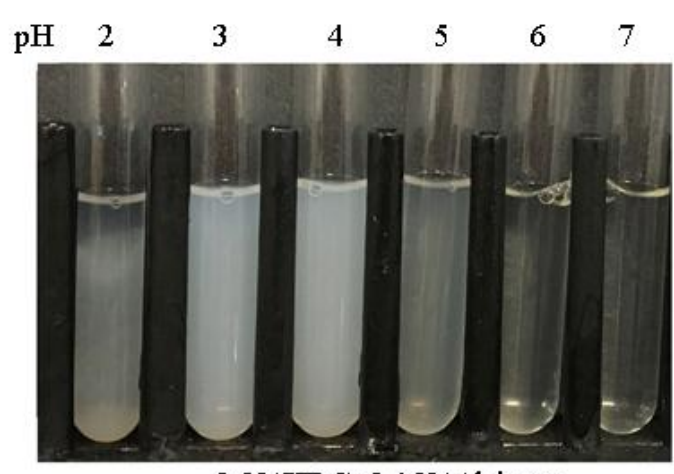

$0.3 \% \mathrm{HRG}+0.15 \%$ Alginate

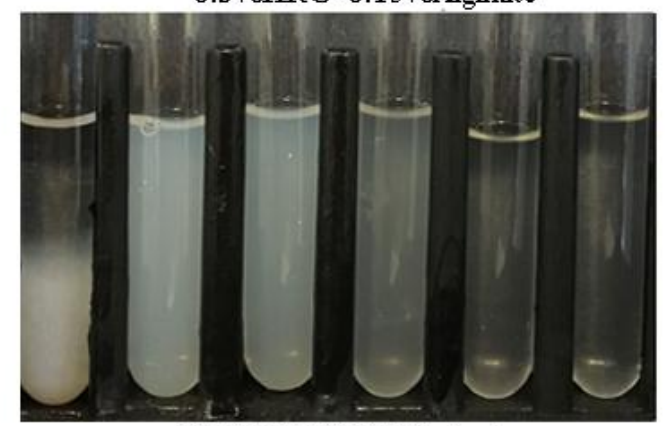

$0.3 \% \mathrm{HRG}+0.2 \%$ Alginate

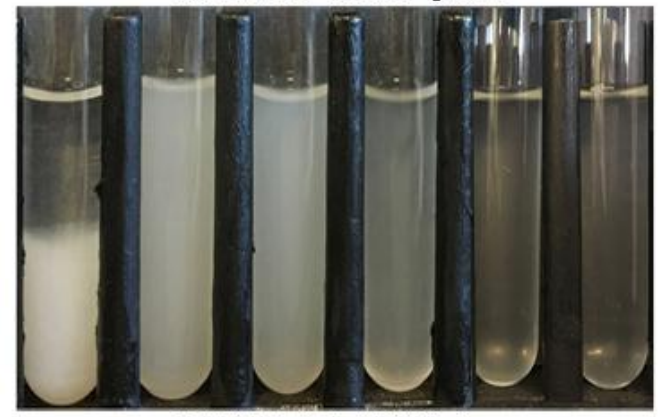

$0.3 \% \mathrm{HRG}+0.25 \%$ Alginate 
Fig.2

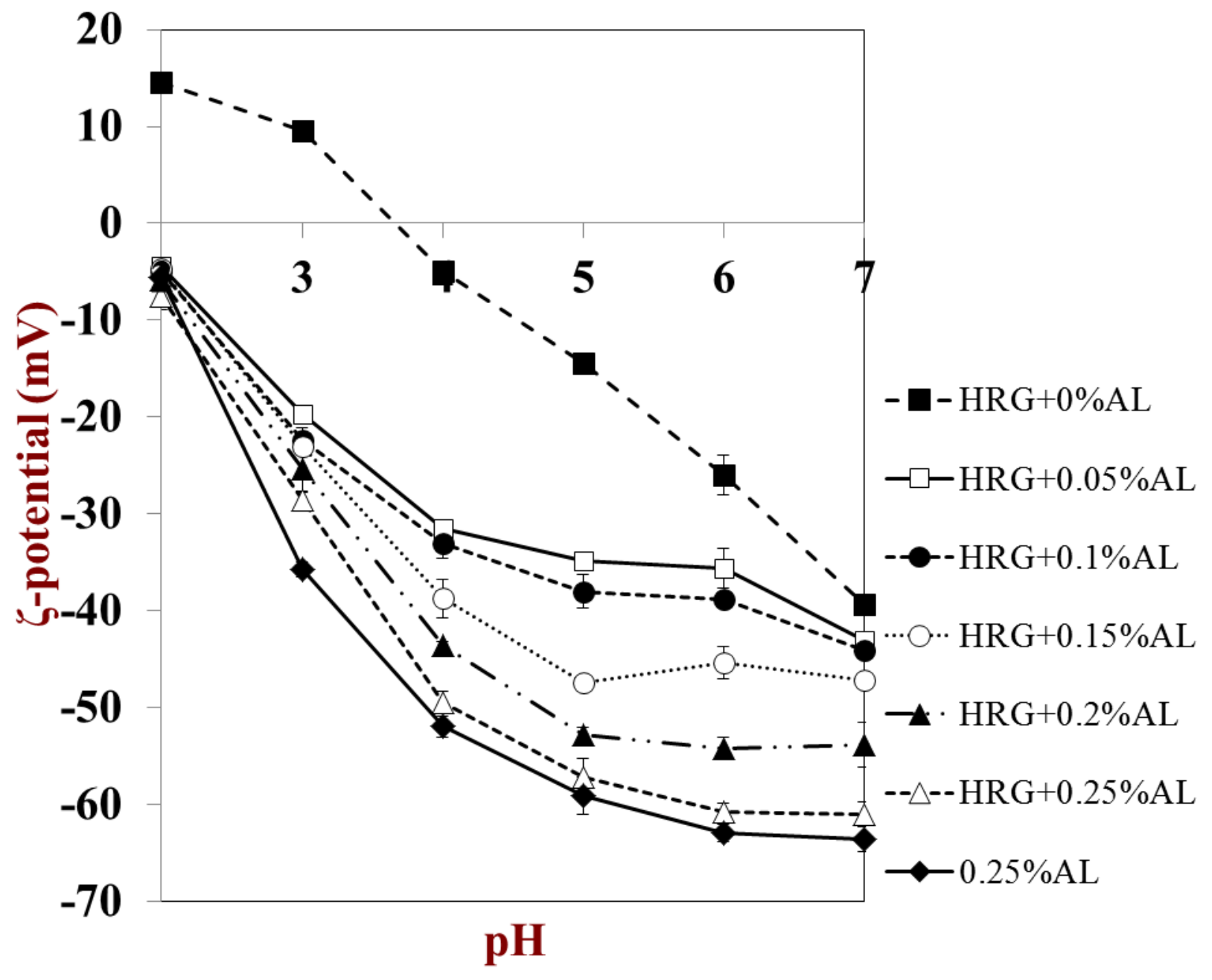


Fig.3

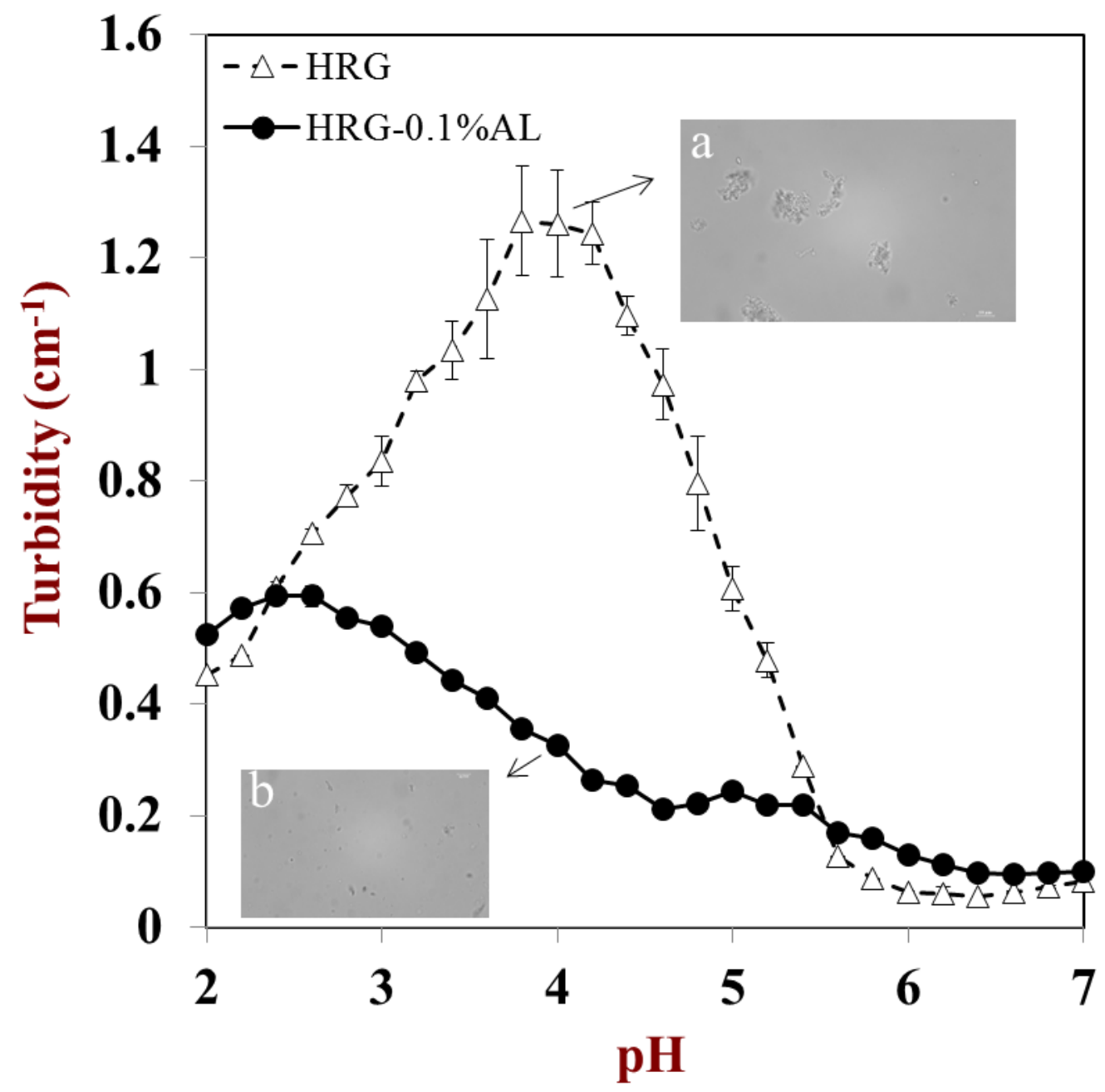


Fig.4a

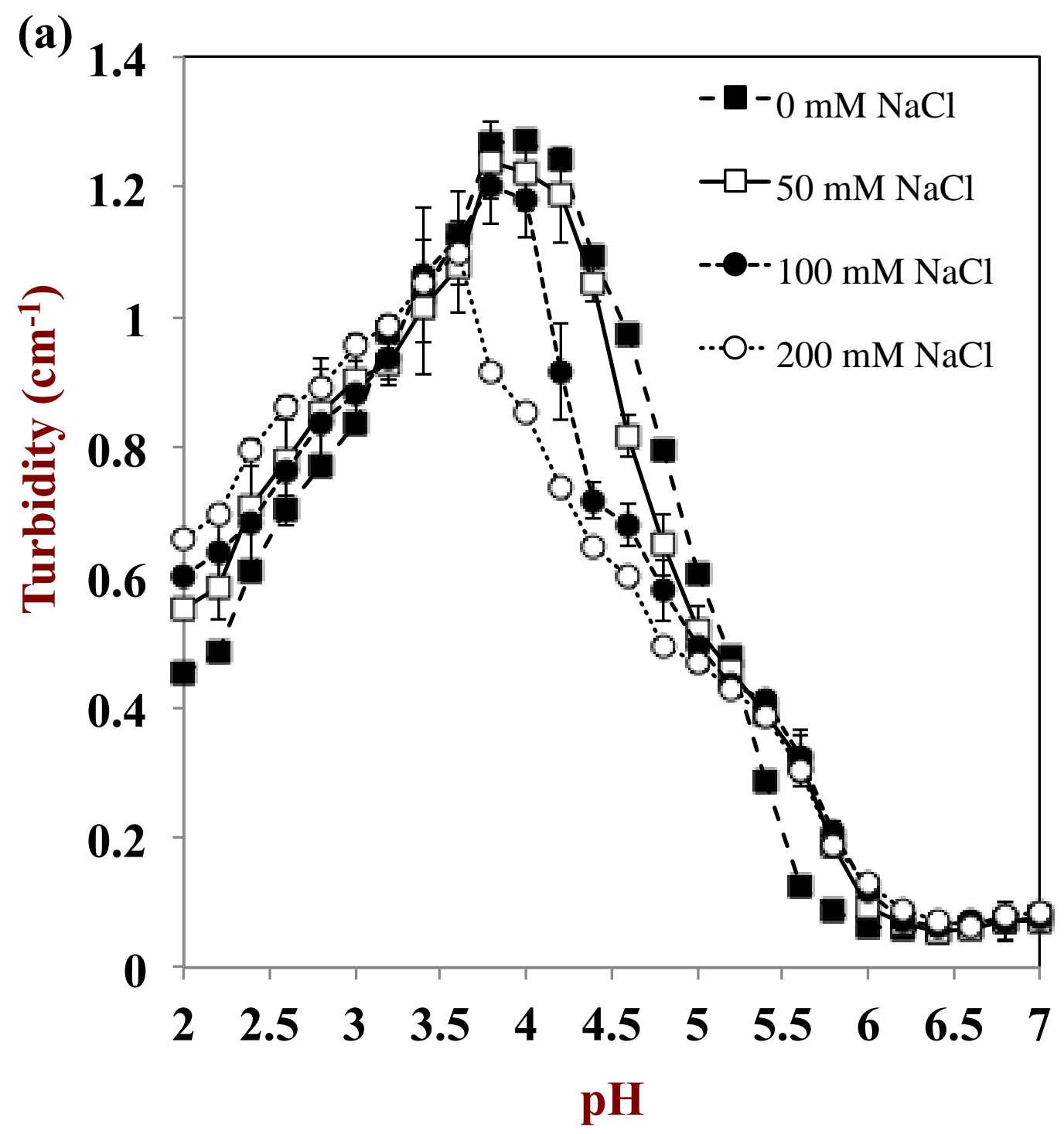


Fig.4b

(b)

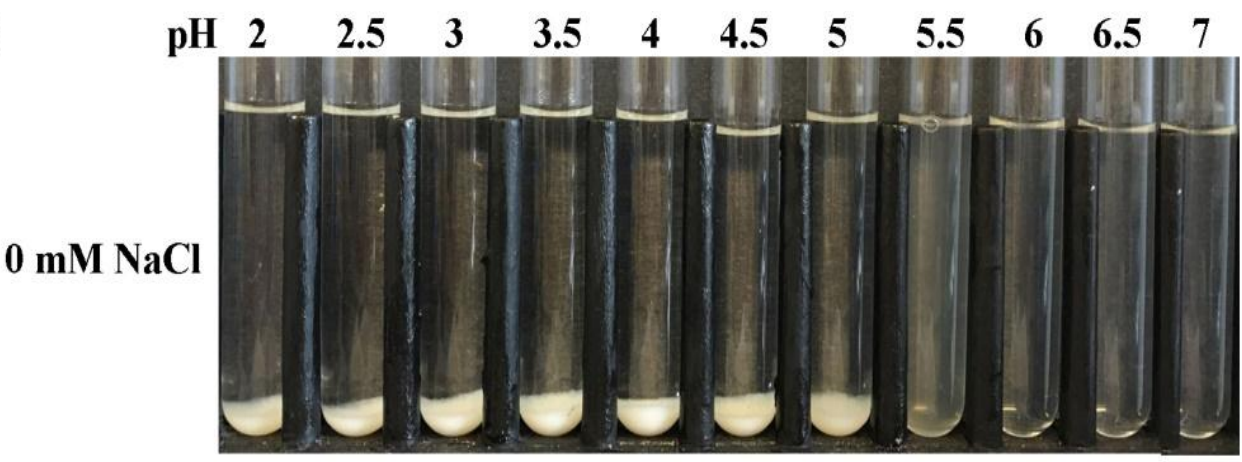

$50 \mathrm{mM} \mathrm{NaCl}$

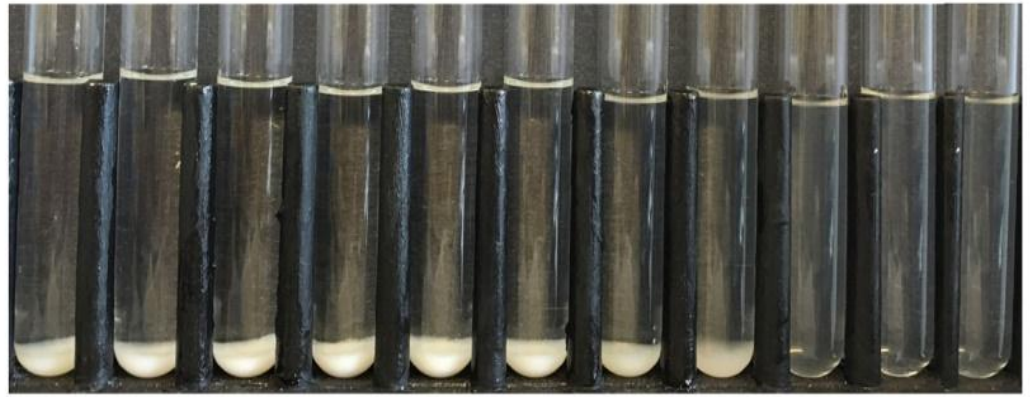

$100 \mathrm{mM} \mathrm{NaCl}$

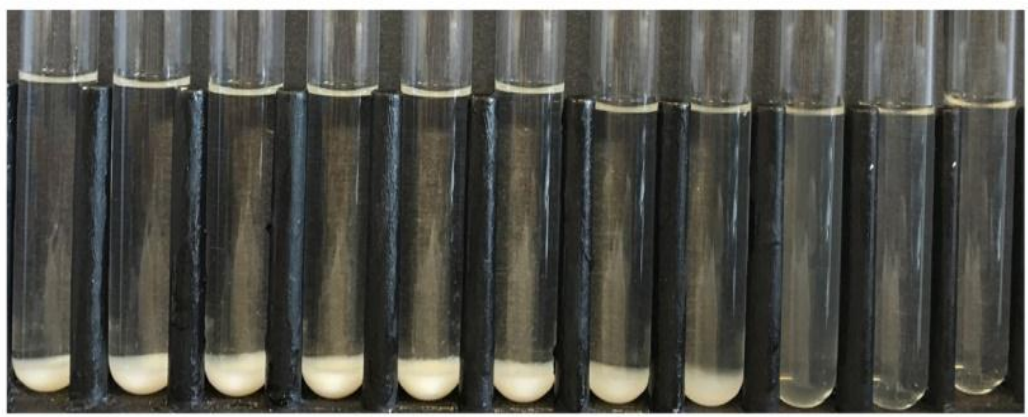

$200 \mathrm{mM} \mathrm{NaCl}$

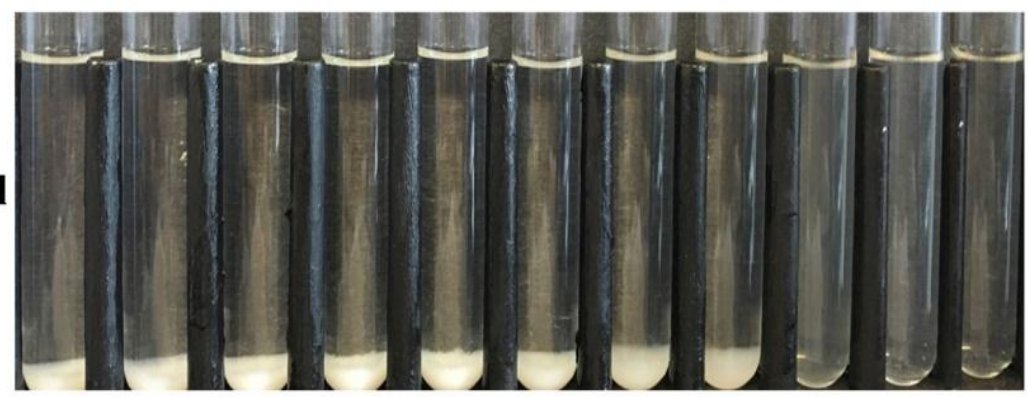

$0.3 \%$ HRG 
Fig.5

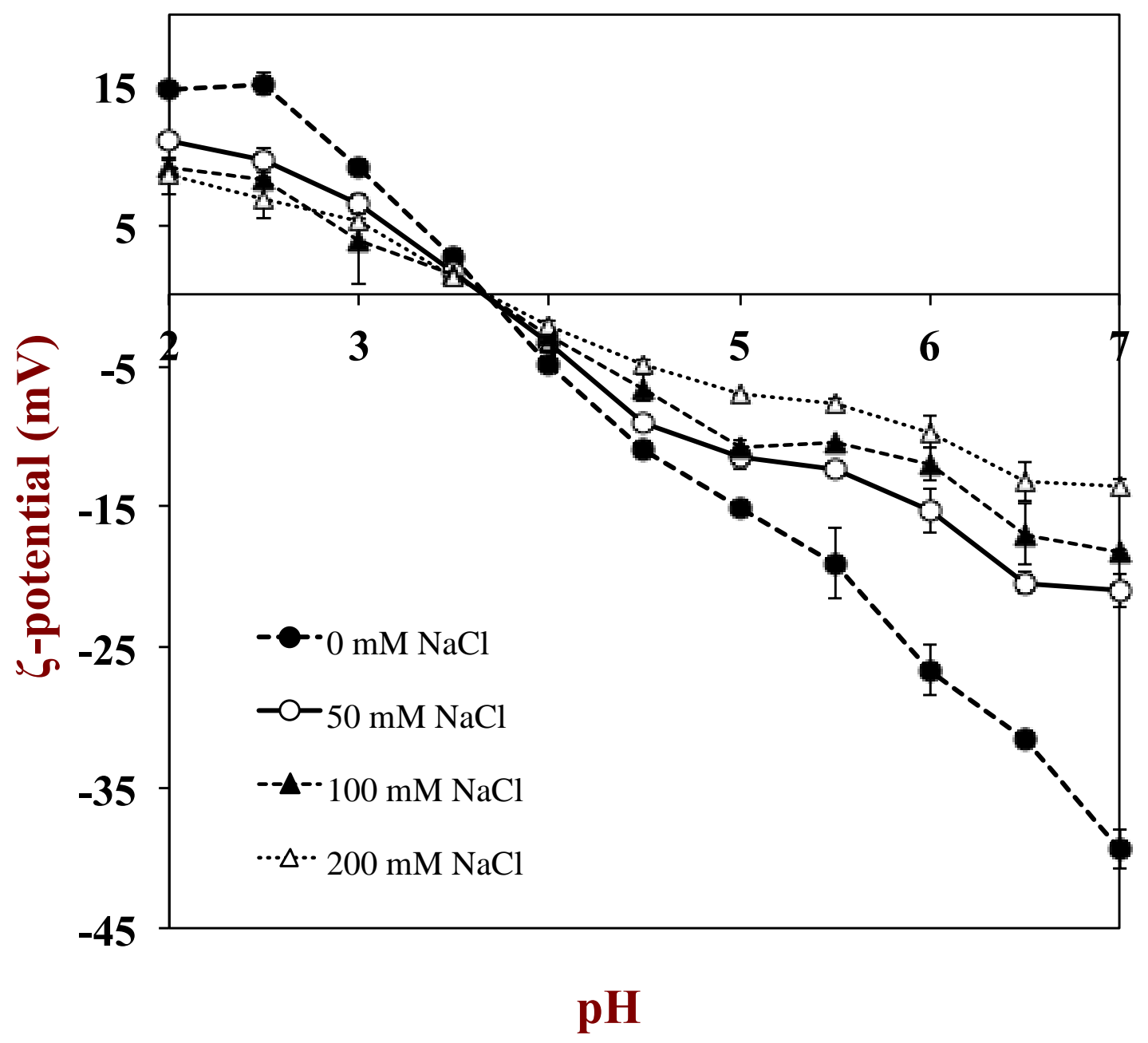


Fig.6a

(a)

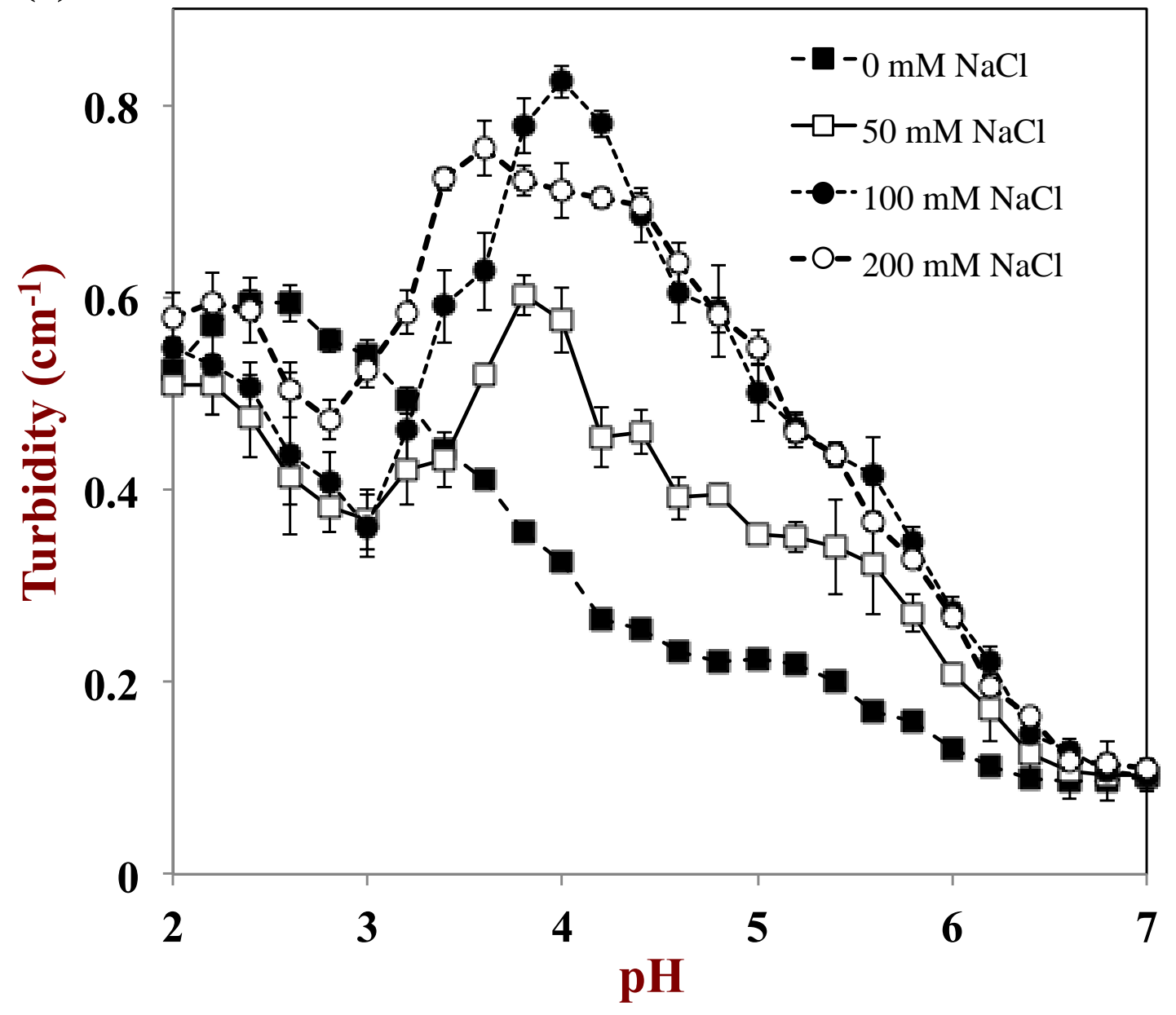


Fig.6b

(b)
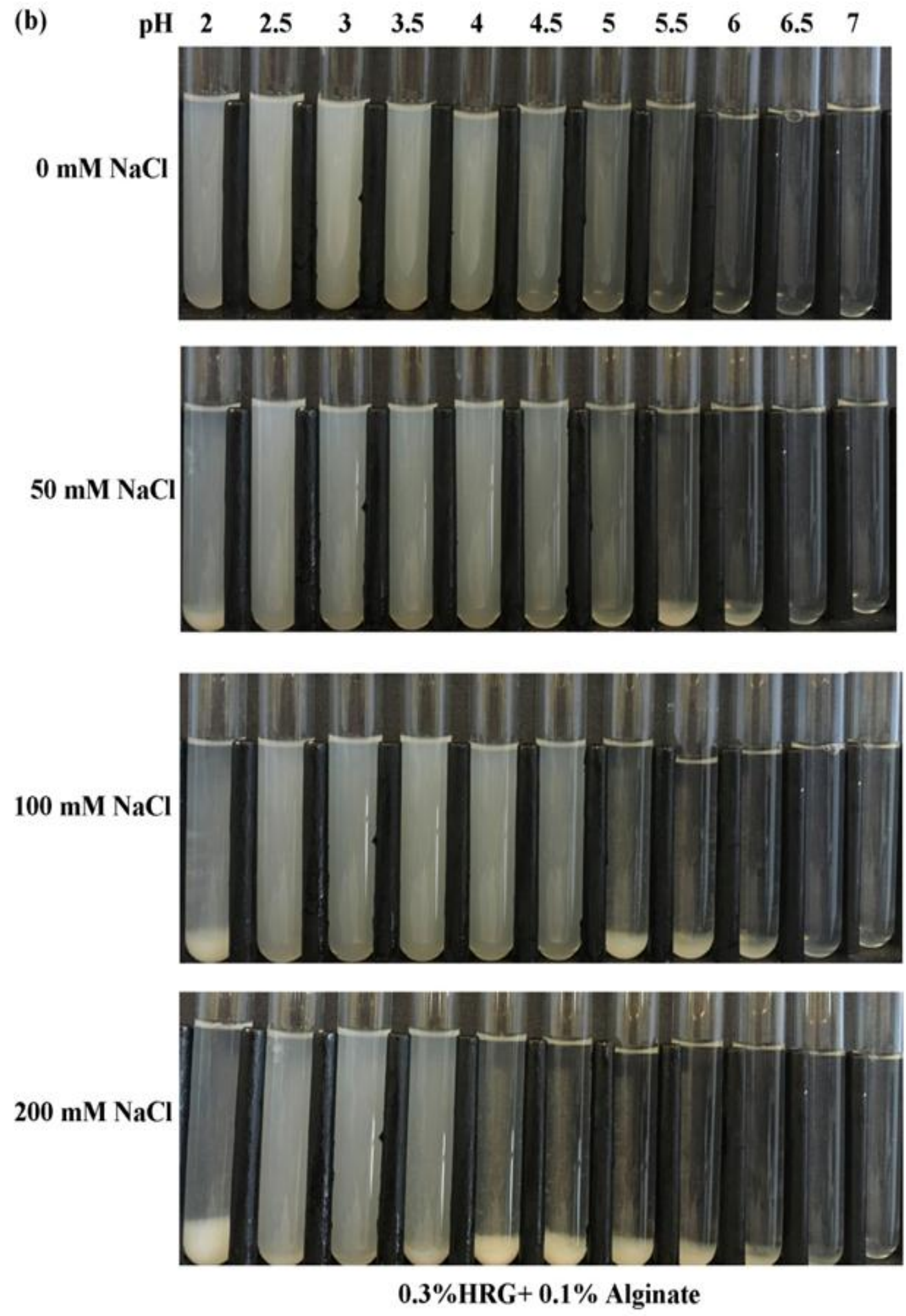
Fig. 7

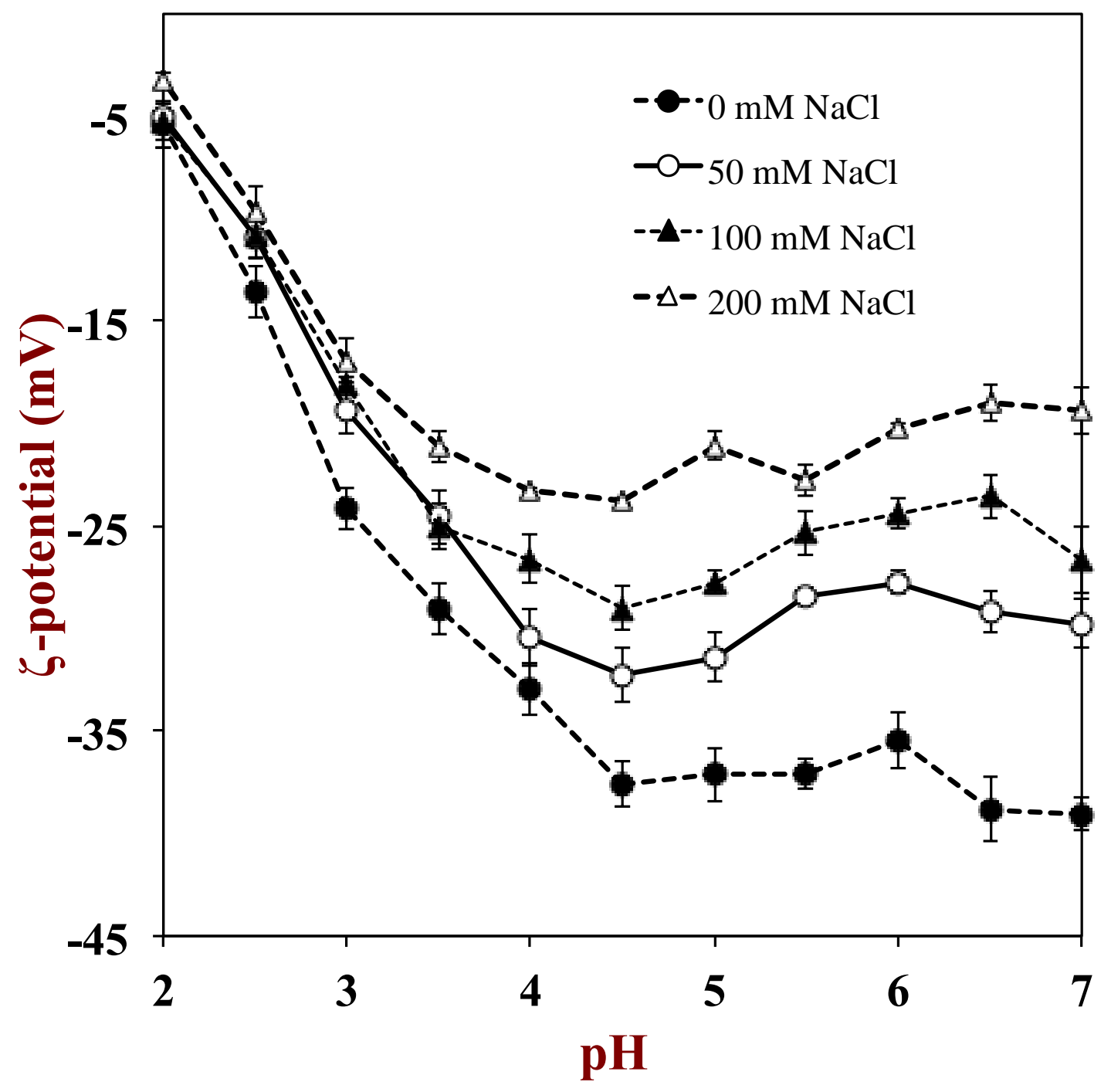


"Influence of Electrostatic Interactions on Behavior of Mixed Rice Glutelin and Alginate Systems: $\mathrm{pH}$ and Ionic Strength Effects"

$\mathrm{Xu}$ et al

Food Hydrocolloids

\section{Graphical Abstract}

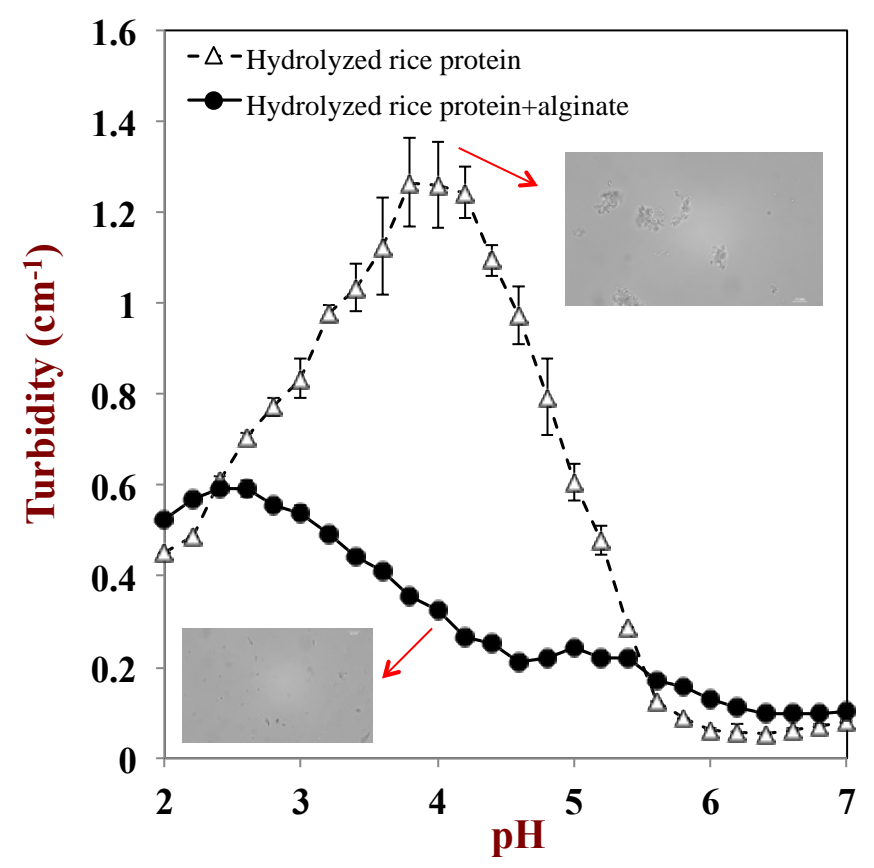

